\title{
Tetrahydroaminoacridine (THA) reduces voltage-dependent calcium currents in rat sensory neurons
}

\author{
Kevin M. Kelly ${ }^{1}$, Robert A. Gross ${ }^{1 *}$ and Robert L. Macdonald ${ }^{1,2}$ \\ Departments of ${ }^{1}$ Neurology and ${ }^{2}$ Physiology, University of Michigan Medical Center, Ann Arhor, Michigan 48109 (U.S.A.) \\ (Received 22 May 1991: Revised version received 11 July 1991; Accepted 25 July 1991)
}

Key words: Tetrahydroaminoacridine; Tacrine; Alzheimer"s disease: Calcium current: Whole cell patch clamp

\begin{abstract}
Tetrahydroaminoacridine (THA) is a centrally active anticholinesterase that also interacts with neuronal $\mathrm{K}^{+}$and $\mathrm{Na}^{+}$channels and cardiac $\mathrm{Ca}^{2+}$ channels. The effects of THA on neuronal voltage-dependent $\mathrm{Ca}^{2+}$ channels are not known. We tested the effects of THA (25 nM-250 $\left.\mu \mathrm{M}\right)$ on the $\mathrm{Ca}^{2+}$ current components of acutely dissociated rat nodose ganglion and dorsal root ganglion (DRG) neurons using the whole cell patch clamp recording technique. THA reduced the low-threshold $(\mathrm{T})$ and high-threshold $(\mathrm{N} / \mathrm{L}) \mathrm{Ca}^{2+}$ current components in a concentration-dependent manner $\left(\mathrm{IC}_{50} \cong 125 \mu \mathrm{M}\right.$ for $\mathrm{T}: \cong 80 \mu \mathrm{M}$ for $\mathrm{N} / \mathrm{L}$ ). Minimal current reduction was seen below $\sim 10 \mu \mathrm{M}$. Our results show that THA reduces voltage-dependent $\mathrm{Ca}^{2+}$ currents in rodent sensory neurons suggesting another means by which THA may affect $\mathrm{Ca}^{2+}$-dependent physiologic processes.
\end{abstract}

Tetrahydroaminoacridine (THA) is a centrally active anticholinesterase that has been tested in the palliative treatment of patients with Alzheimer's disease [6,21]. In addition to its anticholinesterase activity, THA is known to have effects on several types of neuronal voltage-dependent ion channels. THA is structurally related to 4aminopyridine. a $\mathrm{K}^{+}$channel blocker, and has been shown to block $\mathrm{K}^{+}$currents in several studies $[1,3,4$, $7,10,12,13,15,16,18,20]$. THA can also block inward $\mathrm{Na}^{+}$currents [16] and inhibit $\mathrm{Na}^{+}$inactivation [18]. In studies of guinea pig ventricular myocytes [15] and rabbit sinoatrial node [13], THA reduced slow inward voltage-dependent $\mathrm{Ca}^{2+}$ currents. The effects of THA on neuronal voltage-dependent $\mathrm{Ca}^{2+}$ currents are not known.

We examined the effect of THA on the $\mathrm{Ca}^{2+}$ current components of acutely dissociated rat nodose and dorsal root ganglion (DRG) neurons using the whole cell patch clamp technique. These neurons have $\mathrm{Ca}^{2+}$ current components $[2,9,19]$ similar to those initially described in chick DRG neurons [5] and subsequently in mouse DRG neurons [8]. These $\mathrm{Ca}^{2+}$ current components include a transient low-threshold current $(\mathrm{T})$, a transient high-threshold current $(\mathrm{N})$, and a slowly inactivating

'Present address: Department of Neurology. University of Minnesota Medical Center, Minneapolis, MN 55455-0323, U.S.A.

Correspondence: K.M. Kelly, Neuroscience Laboratory Building. University of Michigan, 1103 E. Huron St., Ann Arbor, MI 481041687. U.S.A. high-threshold current (L). Our results show that THA reduced $\mathrm{T}$ and $\mathrm{N} / \mathrm{L} \mathrm{Ca}^{2+}$ currents in rat nodose and DRG neurons.

Nodose ganglia were taken from 5-10-day-old rats, placed in oxygenated $\mathrm{Ca}^{2+}$ - and $\mathrm{Mg}^{2+}$-free buffer, treated with collagenase $(1 \mathrm{mg} / \mathrm{ml})$, and incubated at $37^{\circ} \mathrm{C}$ in a $93 \%$ air $7 \% \mathrm{CO}_{2}$ atmosphere for $30 \mathrm{~min}$. Following addition of enzyme inhibitor (5\% fetal calf serum), the neurons were triturated, centrifuged, resuspended, plated, and reincubated prior to use. DRGs were taken from 15-25-day-old animals ( $\sim 20$ ganglia animal), placed in Minimal Essential Medium (MEM), minced with micro-dissecting scissors, treated with collagenase $(3 \mathrm{mg} / \mathrm{ml})$, and incubated for $50 \mathrm{~min}$ before addition of trypsin $(1 \mathrm{mg} / \mathrm{ml})$, with continued incubation for $10 \mathrm{~min}$. The ganglia were removed, placed in MEM, centrifuged, triturated, recentrifuged, resuspended, plated, and reincubated prior to use.

Recordings of $\mathrm{Ca}^{2+}$ currents were made with glass micropipettes (1.5-2.5 M $\Omega$ ) filled with a solution of (in $\mathrm{mM})$ : $\mathrm{CsCl} 140, \mathrm{CsOH} 30$, HEPES 10, EGTA 10, ATP 5 and GTP 0.1 (pH 7.2-7.3, 300 mOsm). Neurons were bathed in a solution of (in $\mathrm{mM}$ ): choline $\mathrm{Cl} 67$. TEA 100, glucose 5.6, $\mathrm{KCl} 5.3, \mathrm{CaCl}_{2} 5.0, \mathrm{MgCl}_{2} 0.8$, HEPES $10(\mathrm{pH} \mathrm{7.35,} \sim 320 \mathrm{mOsm})$. Cesium and TEA were used to block $\mathrm{K}^{+}$currents; choline was used to block $\mathrm{Na}^{+}$currents. Following sealing of the micropipette to the neuron and rupture of the membrane patch, the neuron was hyperpolarized to a holding potential 
$\left(V_{h}\right)=-90 \mathrm{mV}$ to remove steady-state inactivation of $\mathrm{Ca}^{2+}$ currents. The program pCLAMP (Axon Instruments) was used to generate voltage step commands and to digitize $(5.6 \mathrm{kHz})$ and store current traces. All experiments were conducted at room temperature.

$T$ currents were isolated by evoking currents from a $V_{h}=-90 \mathrm{mV}$ at clamp potentials $\left(V_{c}\right)$ at or positive to $-55 \mathrm{mV}$. Typically, $\mathrm{T}$ currents were evoked by using voltage steps of $100 \mathrm{~ms}$ duration delivered every $5 \mathrm{~s}$ in $5 \mathrm{mV}$ increments ranging from a $\mathrm{V}_{\mathrm{c}}=-65$ to $-20 \mathrm{mV}$. T currents were measured at the point of peak inward current and at $100 \mathrm{~ms}$. Maximal $T$ current was the largest evoked peak $T$ current evoked at a $\mathrm{V}_{\mathrm{c}}$ (usually $-35 \mathrm{mV}$ ) negative to that at which more slowly inactivating current components $(\mathrm{N} / \mathrm{L})$ were evoked. This resulted in slight underestimation of $\mathrm{T}$ current magnitude but allowed for examination of those currents with little highthreshold current contamination. T currents were stable and showed little change in amplitude over the course of an experiment. $T$ current magnitude varied among neurons from barely detectable to greater than $1.5 \mathrm{nA}$.

$\mathrm{N} / \mathrm{L}$ currents were evoked from a $\mathrm{V}_{\mathrm{h}}=-90 \mathrm{mV}$ (occasionally $-80 \mathrm{mV}$ ) at a $V_{c}$ at or positive to $-20 \mathrm{mV}$ and were measured at the point of peak inward current and at $100 \mathrm{~ms}$. Maximal N/L current was the largest evoked high threshold current measured at peak current. Currents were evoked at $1 \mathrm{~min}$ intervals and declined 30 $50 \%$ during a $20 \mathrm{~min}$ recording. Current rundown was estimated for each neuron from serial maximal $\mathrm{N} / \mathrm{L}$ cur- rents evoked at 1 min intervals approximately $5 \mathrm{~min}$ after patch rupture and prior to application of THA.

$\mathrm{T}$ and $\mathrm{N} / \mathrm{L}$ currents were leak subtracted for analysis using the inverse of currents evoked from hyperpolariz. ing voltage commands equal to the depolarizing commands used in evoking inward currents. Current activation, current inactivation, and voltage-dependency were assessed for control and THA. Current activation was estimated using the time to the point of peak inward current. Current inactivation was estimated using the ratio of current at $100 \mathrm{~ms} /$ peak current. Voltage dependency was assessed by inspection of the current-voltage relation.

THA was prepared on the day of experiments by dissolving it in external solution. The THA solution was drawn up into a blunt tipped $(10-15 \mu \mathrm{m})$ micropipette which was kept out of the bath solution when not in use. THA was tested by positioning the micropipette tip $\sim 50$ $\mu \mathrm{m}$ from the cell soma and applied by passive diffusion shortly before and during voltage step commands. The effects of THA applied by pressure ejection ( 1 psi) were the same as those by passive diffusion. Control micropipettes contained external solution and were substituted sequentially with micropipettes containing different concentrations of THA.

THA was tested in 25 neurons: 20 nodose and 5 DRG. There was no observed difference in the effects of THA on the evoked $\mathrm{Ca}^{2+}$ currents for the two neuronal types, so data were pooled for analysis. Fig. 1 shows the con-

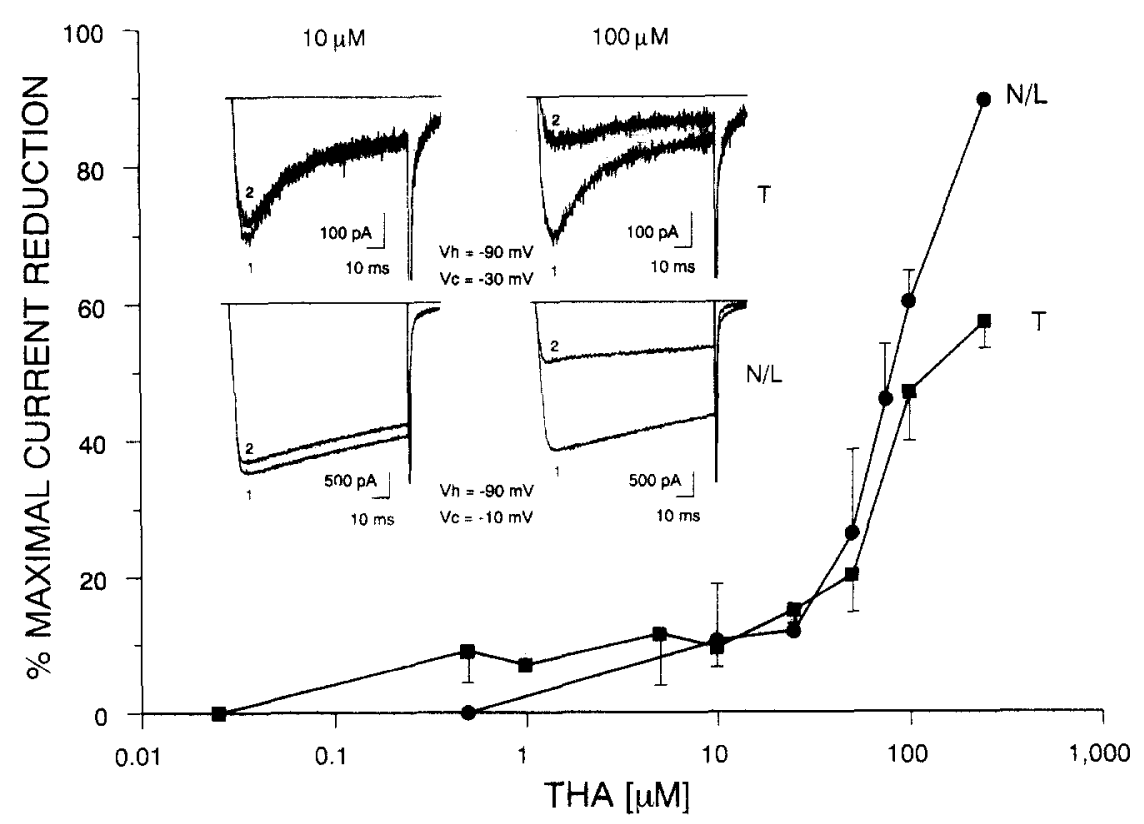

Fig. 1. Concentration-response curves for maximal $\mathrm{T}$ and $\mathrm{N} / \mathrm{L} \mathrm{Ca}^{2+}$ currents tested in 25 nodose and dorsal root ganglion (DRG) neurons with THA $(25 \mathrm{nM}-250 \mu \mathrm{M})$. Each point represents the mean percent reduction of control maximal currents obtained by testing with THA in $\mathrm{I}-4$ neurons (bars indicate S.E.M.). For each neuron studied, specific concentrations of THA were tested by single or multiple applications. Inset: leak-subtracted $\mathrm{T}$ and $\mathrm{N} / \mathrm{L}$ currents in a nodose neuron for control (1) and THA (2) at $10 \mu \mathrm{M}$ and $100 \mu \mathrm{M}$. 


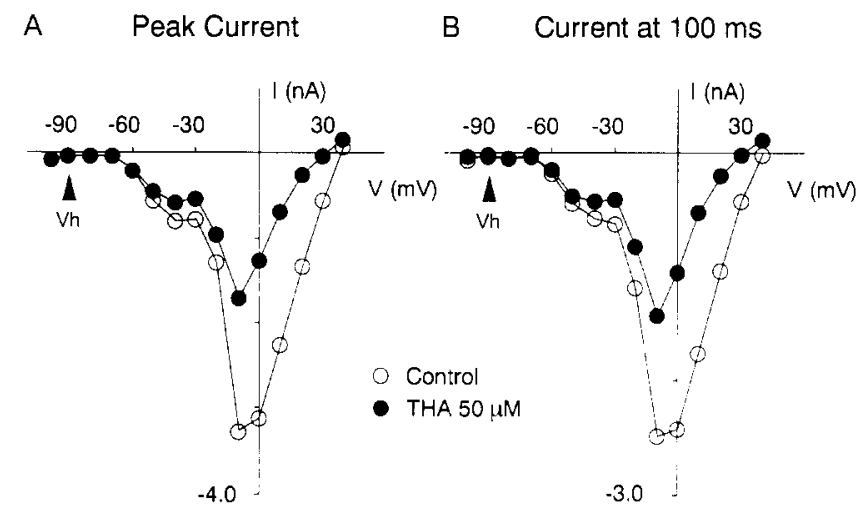

Fig. 2. Current-voltage relations for $\mathrm{Ca}^{2}+$ currents measured in a DRG neuron in the absence and presence of THA (50 $\left.\mu \mathrm{M}\right)$. Ca ${ }^{2+}$ currents were evoked from a $V_{h}=-90 \mathrm{mV}$ at a $V_{c}$ ranging from -100 to $+40 \mathrm{mV}$. A: THA's effect on peak current amplitude. B: THA's effect on the current amplitude measured at $100 \mathrm{~ms}$ (note change in ordinate scale).

vous system have an increased sensitivity to THA. Beneficial effects have been reported for nimodipine, a dihycentration-response curve of THA $(25 \mathrm{nM}-250 \mu \mathrm{M})$ on maximal $\mathrm{T}$ and $\mathrm{N} / \mathrm{L}$ current reduction for all neurons studied. THA decreased peak current in a concentrationdependent manner for both $\mathrm{T}\left(\mathrm{IC}_{50} \cong 125 \mu \mathrm{M}\right)$ and $\mathrm{N} / \mathrm{L}$ $\left(\mathrm{IC}_{50} \cong 80 \mu \mathrm{M}\right)$ currents. Minimal current reduction was seen below $\sim 10 \mu \mathrm{M}$. At the highest concentration tested $(250 \mu \mathrm{M}), \mathrm{T}$ current was reduced by $57 \%$, and $\mathrm{N} / \mathrm{L}$ current by $90 \%$. Fig. 1 (inset) demonstrates the concentration-dependent reduction of $T$ and $N / L$ currents in a nodose neuron by THA $(10 \mu \mathrm{M}$ and $100 \mu \mathrm{M})$. T currents recovered fully within $1 \mathrm{~min}$ of THA application. N/L currents recovered fully within 1 min with THA $(10 \mu \mathrm{M})$, but took $3 \mathrm{~min}$ to recover with THA $(100 \mu \mathrm{M})$ (not shown). Current activation was not changed with THA. Similarly, the amount of current inactivation was not changed with THA (10 $\mu \mathrm{M})$, however, current inactivation appeared to decrease with THA at higher concentrations $(100 \mu \mathrm{M})$, an effect seen in other neurons as well. This suggests that the apparent decreased inactivation for $T$ currents was due to either the late current consisting of a $T$ current and a reduced $\mathrm{N} / \mathrm{L}$ current component or that there were two phases of $\mathrm{T}$ current inactivation with the THA effect greater on the initial, larger component. For $\mathrm{N} / \mathrm{L}$ currents, the initial current was reduced to a greater extent than late $(100 \mathrm{~ms})$ currents. This could be due to greater reduction of the more rapidly inactivating $\mathrm{N}$ current than the slowly inactivating $\mathrm{L}$ current by THA or that THA causes a small increase in activation rate. Fig. 2 shows the current-voltage relation for $\mathrm{Ca}^{2+}$ currents measured at peak current (A) and at $100 \mathrm{~ms}$ (B) when tested with THA $(50 \mu \mathrm{M})$. THA did not change the voltage-dependency of the evoked currents at peak or $100 \mathrm{~ms}$.

The main finding of this study was that THA reversibly reduced whole cell voltage-dependent $\mathrm{T}$ and $\mathrm{N} / \mathrm{L}$
$\mathrm{Ca}^{2+}$ currents in a concentration-dependent manner in rat nodose and DRG neurons. These results demonstrate that in addition to THA's known anticholinesterase activity and its effects on $\mathrm{K}^{+}$and $\mathrm{Na}^{+}$currents in neuronal preparations, it can also cause marked reduction of neuronal voltage-dependent $\mathrm{Ca}^{2+}$ currents. $\mathrm{Ca}^{2+}$ current reduction occurred without effect on current activation or inactivation, or on voltage dependency at THA concentrations $\leqslant 75 \mu \mathrm{M}$. Several studies have shown THA's ability to block different $\mathrm{K}^{+}$conductances but THA has little to no effect on $\mathrm{Ca}^{2+}$-activated $\mathrm{K}^{+}$conductances $[1,3,20]$. Thus the block of $\mathrm{Ca}^{2+}$ currents seen in these experiments probably does not contribute to a secondary reduction of $\mathrm{K}^{+}$currents. THA's reduction of both $T$ and $N / L$ currents suggests that it may have diverse effects on $\mathrm{Ca}^{2+}$-dependent physiologic processes. $\mathrm{N}$ currents may be primary regulators of the inhibition of release of neurotransmitters [11] and reduction of these currents by THA may contribute to the observed inhibitory effect of THA on depolarizationinduced release of $\gamma$-aminobutyric acid (GABA) in rat cerebral cortex [3]. THA's reduction of cardiac slow inward $\mathrm{Ca}^{2+}$ currents $[13,15]$ is likely mediated by Ltype $\mathrm{Ca}^{2+}$ channels and $\mathrm{Ca}^{2+}$ current reduction in those studies may be qualitatively similar to the results found here.

THA had little effect on $\mathrm{Ca}^{2+}$ currents in the serum concentration range $(20-300 \mathrm{nM})$ used in clinical trials in the treatment of Alzheimer's disease [21]. Although rodent in vivo levels of THA have been shown to be 10 times higher in brain than plasma [14], a log unit shift of the THA concentration-response curve in the present experiments would not have been significant since minimal current reduction was seen below $\sim 10 \mu \mathrm{M}$. This result suggests that if THA has any therapeutic effect in Alzheimer's disease, it is not likely due to reduction of $\mathrm{Ca}^{2+}$ currents unless $\mathrm{Ca}^{2+}$ channels in the central ner- 
dropyridine derivative and $\mathrm{Ca}^{2+}$ channel antagonist, in the management of primary degenerative dementia [22] and in animal models of aging and cognition [17].

We thank Mr. Sean C. Hanson for preparation of the cell cultures. Supported in part by an American Academy of Neurology Research Fellowship Award and a CIDA to K.M.K. NS 01019 and NS 19613 to R.A.G. and DA04122 to R.L.M.

1 Brown, D.A., Grove, E.A. and Halliwell, J.V., Tetrahydroaminoacridine (THA) blocks the Q-current in hippocampal CAl neurones, Neurosci. Lett., 32 Suppl. (1988) S8.

2 Carbone, E. and Lux, H.D., Kinetics and selectivity of a low-voltage-activated calcium current in chick and rat sensory neurones, J. Physiol, 386 (1987) 547-570.

3 De Belleroche, J. and Gardiner, I.M., Inhibitory effect of 1,2,3,4tetrahydro-9-aminoacridine on the depolarization-induced release of GABA from cerebral cortex, Br. J. Pharmacol.. 94 (1988) 10171019.

4 Drukarch, B., Kits, K.S., Van der Meer, E.G., Lodder, J.C. and Stoof, J.C., 9-Amino-1,2,3,4-tetrahydroacridine (THA), an alleged drug for the treatment of Alzheimer's disease, inhibits acetylcholinesterase activity and slow outward $\mathrm{K}^{+}$current, Eur. J. Pharmacol., 141 (1987) 153-157.

5 Fox, A.F., Nowycky, M.C. and Tsien, R.W., Kinetic and pharmacological properties distinguishing three types of calcium currents in chick sensory neurones, J. Physiol., 394 (1987) 149-172.

6 Gauthier, S., Bouchard, R., Lamontagne, A., Bailey, P., Bergman, H., Ratner, J., Tesfaye, Y., Saint-Martin, M., Bacher, Y., Carrier, L., Charbonneau, R., Clarfield, A.M., Collier, B., Dastoor, D., Gauthier, L., Germain, M., Kissel, C., Krieger, M., Kushnir, S., Masson, H., Morin, J., Nair, V., Neirinck, L. and Suissa, S., Tetrahydroaminoacridine-lecithin combination treatment in patients with intermediate-stage Alzheimer's disease: results of a Canadian double-blind, crossover, multicenter study, N. Engl. J. Med., 322 (1990) 1272-1276.

7 Griffith, W.H. and Sim, J.A., Comparison of 4-aminopyridine and tetrahydroaminoacridine on basal forebrain neurons. J. Pharmacol. Exp. Ther., 255 (1990) 986-993.

8 Gross, R.A. and Macdonald, R.L., Differential actions of pentobarbitone on calcium current components of mouse sensory neurones in culture, J. Physiol., 405 (1988) 187-203.

9 Gross, R.A., Uhler, M.D. and Macdonald, R.L., The cyclic AMPdependent protein kinase catalytic subunit selectively enhances cal- cium currents in rat nodose neurones, J. Physiol. $429(1990) 483$ 496.

10 Halliwell, J.V. and Grove, E.A., 9-Amino-1,2.3,4-tetrahydroacridine (THA) blocks agonist-induced potassium conductance in rat hippocampal neurones, Eur. J. Pharmacol., 163 (1989) 369-372.

11 Hirning, L.D., Fox, A.P., McCleskey, E.W., Olivera, B.M., Thayer, S.A., Miller, R.J. and Tsien, R.W.. Dominant role of Ntype of $\mathrm{Ca}^{++}$channels in evoked release of norepinephrine from rat sympathetic neurons, Science, 239 (1988) 57.61.

12 Kotake, H., Hisatome, I., Matsuoka, S., Miyakoda, H., Hasegawa, J. and Mashiba, H., Inhibitory effect of 9-amino-1,2,3,4-tetrahydroacridine (THA) on the potassium current of rabbit sinoatrial node, Cardiovasc. Res., 24 (1990) 42-46.

13 Kotake, H., Noguchi, N., Doi, T., Matsuoka, S., Hisatome, 1., Hasegawa. J. and Mashiba, H., An electrophysiological study of 9amino-1,2,3,4-tetrahydroacridine (THA) on sino-atrial node preparations of rabbits, Gen. Pharmacol., 21 (1990) 489-492.

14 Nielsen, J.A., Mena, E.E., Williams, I.H., Nocerini, M.R. and Liston, D., Correlation of brain levels of 9-amino-1,2,3,4-tetrahydroacridine (THA) with neurochemical and behavioral changes, Eur. J. Pharmacol., 173 (1989) 53-64.

15 Osterrieder, W., 9-Amino-1,2,3,4-tetrahydroacridine (THA) is a potent blocker of cardiac potassium channels, Br. J. Pharmacol., 92 (1987) 521-525.

16 Rogawski, M.A., Tetrahydroaminoacridine blocks voltage-dependent ion channels in hippocampal neurons, Eur. J. Pharmacol., 142 (1987) $169-172$.

17 Sandin, M., Jasmin, S. and LeVere, T.E., Aging and cognition: facilitation of recent memory in aged nonhuman primates by nimodipine, Neurobiol. Aging, 11 (1990) 573-575.

18 Schauf, C.L. and Sattin, A., Tetrahydroaminoacridine blocks potassium channels and inhibits sodium inactivation in Myxicola. J. Pharmacol. Exp. Ther., 243 (1987) 609-613.

19 Schroeder, J.E., Fischbach, P.S., Mamo, M. and McCleskey, E.W., Two components of high-threshold $\mathrm{Ca}^{2}+$ current inactivate by different mechanisms, Neuron, 5 (1990) 445-452.

20 Stevens, D.R. and Cotman, C.W., Excitatory actions of tetrahydro-9-aminoacridine (THA) on hippocampal pyramidal neurons, Neurosci. Lett., 79 (1987) 301-305.

21 Summers, W.K., Majovski, L.V., Marsh, G.M., Tachiki, K. and Kling, A., Oral tetrahydroaminoacridine in long-term treatment of senile dementia, Alzheimer type, N. Engl. J. Med., 315 (1986) 1241 1245.

22 Tollefson, G.D., Short-term effects of the calcium channel blocker nimodipine (Bay-e-9736) in the management of primary degenerative dementia, Biol. Psych., 27 (1990) 1133-1 142. 